\title{
The Totality of Evidence and Use of ABP 215, a Biosimilar to Bevacizumab
}

Jerome Goldschmidt · Vladimir Hanes

Received: September 30, 2020 / Accepted: October 24, 2020 / Published online: December 17, 2020

(C) The Author(s) 2020

\section{ABSTRACT}

ABP 215 (MVASI $^{\mathrm{TM}}$, Amgen, Thousand Oaks, CA; MVASI ${ }^{\mathrm{TM}}$, Amgen Europe B.V., Netherlands) is a biosimilar to bevacizumab (Avastin ${ }^{\circledR}$, Genentech, South San Francisco, CA) reference product (RP), a monoclonal antibody targeting vascular endothelial growth factor A (VEGF-A). Here we provide a brief overview of the totality of evidence that supported the approval of ABP 215 , along with practical considerations to ensure safe and effective administration.

ABP 215 has been shown to be highly similar to the RP, with similar mechanism of action, analytical (structural and functional) characteristics, binding, and potency. The similarity of PK parameters of ABP 215 and bevacizumab RP has been confirmed in healthy volunteers.

Electronic Supplementary Material The online version of this article (https://doi.org/10.1007/s40487020-00133-1) contains supplementary material, which is available to authorized users.

J. Goldschmidt ( $\square)$

Oncology and Hematology Associates of Southwest

Virginia, US Oncology Research, McKesson Specialty

Health, Blacksburg, VA, USA

e-mail: Jerome.Goldschmidt@usoncology.com

V. Hanes

Amgen Inc., 1 Amgen Center Drive, Thousand Oaks, CA 91320, USA
In a comparative clinical trial, patients with stage IV or recurrent non-squamous non-small cell lung cancer receiving carboplatin and paclitaxel were randomized to ABP 215 or bevacizumab RP. No clinically meaningful differences were found between ABP 215 and RP. The objective response rate (ORR) was 39\% for ABP 215 and 41.7\% for bevacizumab RP. The risk ratio for the ORR was 0.93 [90\% confidence interval (CI), 0.80-1.09], which fell within the prespecified margin for equivalence of $0.67-1.5$, indicating similar clinical efficacy.

Similar to bevacizumab RP, ABP 215 is supplied as a clear to slightly opalescent, colorless to pale yellow, sterile solution in a glass vial. It should be diluted in $0.9 \%$ sodium chloride in polyvinylchloride or polyolefin bags before administering as an intravenous infusion. The ABP 215 solution should be stored at $2-8{ }^{\circ} \mathrm{C}$ $\left(36-46^{\circ} \mathrm{F}\right)$ prior to use. Physicochemical stability studies showed that there were no meaningful changes in purity or potency and no loss of protein after storage at $2-8{ }^{\circ} \mathrm{C}$ for 35 days followed by storage at $30^{\circ} \mathrm{C}$ for $48 \mathrm{~h}$.

Keywords: ABP 215; Cervical cancer; Colorectal cancer; Epithelial ovarian cancer; Fallopian tube cancer; Glioblastoma; Nonsmall cell lung cancer; Primary peritoneal cancer; Renal cell carcinoma 


\section{Key Summary Points}

ABP215 (MVASI ${ }^{\mathrm{TM}}$ ) is a biosimilar to bevacizumab reference product (RP).

It is highly similar to the RP in analytical characteristics and, like the RP, binds with high affinity to vascular endothelial growth factor A (VEGF-A), resulting in subsequent inhibition of its binding to endothelial VEGF receptors and downstream inhibition of angiogenesis and multiple oncogenic pathways.

The pharmacokinetics of ABP 215 are also highly similar to bevacizumab RP.

A comparative clinical trial in patients with stage IV or recurrent non-

squamous non-small cell lung cancer has shown similar pathologic complete response with ABP 215 and bevacizumab $\mathrm{RP}$, with no new safety or immunogenicity concerns.

Like the RP, ABP 215 product is supplied as a clear to slightly opalescent, colorless to pale yellow, sterile solution in a glass vial to be diluted prior to use as intravenous infusion.

The totality of evidence showed that ABP 215 is highly similar to bevacizumab RP, with no clinically meaningful differences, thus supporting extrapolation to all approved indications of the RP and providing an alternative to bevacizumab $\mathrm{RP}$ in the treatment of patients.

\section{DIGITAL FEATURES}

This article is published with digital features, including an animated mechanism of action video and summary slide, to facilitate understanding of the article. To view digital features for this article go to https://doi.org/10.6084/ m9.figshare.13135022.

\section{INTRODUCTION}

ABP 215 (MVASI $^{\mathrm{TM}}$, Amgen, Thousand Oaks, CA; MVASI ${ }^{\mathrm{TM}}$, Amgen Europe B.V., Netherlands) is a biosimilar to bevacizumab (Avastin ${ }^{\circledR}$, Genentech, South San Francisco, CA) reference product (RP), a monoclonal antibody targeting vascular endothelial growth factor A (VEGF-A) $[1,2]$. Bevacizumab binds to VEGF-A and inhibits its binding to, and activation of, its receptors on the exterior of endothelial cells, thereby interfering with angiogenesis and various downstream oncogenic pathways [3, 4] (Fig. 1) (Video: MOA).

Supplementary file Animated mechanism of action video (MP4 $6205 \mathrm{~KB}$ )

ABP 215 is approved in the United States (US) and the European Union (EU) for metastatic colorectal cancer; unresectable, locally advanced, recurrent, or metastatic non-squamous non-small cell lung cancer (NSCLC); metastatic renal cell carcinoma; and persistent, recurrent, and metastatic cervical cancer. Additionally, ABP 215 is approved in the $\mathrm{EU}$ for metastatic breast cancer; non-squamous NSCLC with epidermal growth factor-activating mutations (in combination with erlotinib); and advanced/recurrent epithelial ovarian and fallopian cancer; and in the US for recurrent glioblastoma in adults [1-3].

Biosimilars are similar versions of originator biologics. Biologics are complex molecules that are manufactured using living cells and used in the treatment of several chronic inflammatory diseases and cancer. Access to biologics is limited, and the availability of biosimilars has the potential to provide additional biologic drug options $[5,6]$.

Unlike generic drugs, which are chemically synthesized and identical to their RPs, a biosimilar is structurally and functionally similar to its RP while showing no clinically meaningful differences in safety, purity, or potency $[5,7-12]$. The biological characteristics of the cell lines used in their production and the complexity of manufacturing processes may impact the composition, structure, and stability of the biosimilar [13]. As a result, a biosimilar is both distinct from and similar to its RP. 


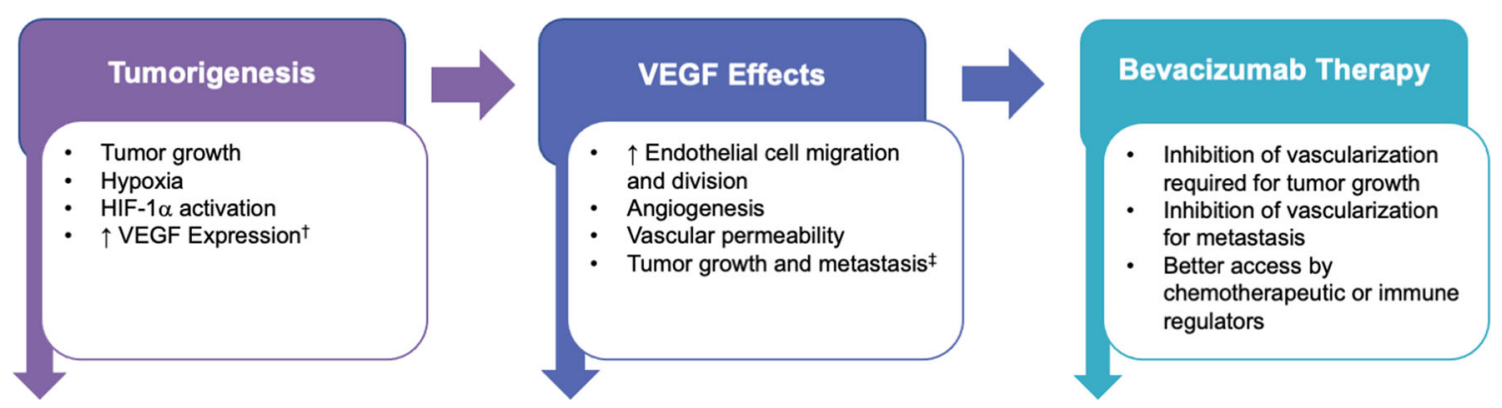

Fig. 1 Summary of the molecular mechanisms affected by bevacizumab [3]. ${ }^{\dagger}$ In addition to tumorigenesis resulting in HIF- $1 \alpha$ activation and elevated VEGF expression, in mRCC, a mutation in the von Hippel-Lindau gene results in elevated expression of HIF-1 $\alpha$, and subsequently VEGF. Also, HPV-induced downregulation of $\mathrm{p} 53$ in cervical cancer leads to a direct increase in VEGF. FThe VEGF

The development of a biosimilar requires extensive, scientifically rigorous, comparative assessments and evaluations. The body of nonclinical, preclinical, and clinical data obtained to demonstrate the similarity of a proposed biosimilar to its RP is referred to as the "totality of evidence" (TOE) and forms the basis for its regulatory approval [5].

This article will provide a brief overview of the TOE for ABP 215 as a biosimilar to bevacizumab RP (Fig. 2) and will discuss practical considerations related to its storage and clinical use. The article is based on previously conducted studies and does not contain any studies with human participants or animals performed by any of the authors.

\section{Totality of Evidence for ABP 215}

As the first step in the development of ABP 215, comprehensive, state-of-the-art analytical assessments were performed to identify any potential structural and functional differences between ABP 215 and bevacizumab RP. For these assessments, the RP was sourced from the US (bevacizumab US) and the EU (bevacizumab EU). ABP 215 and bevacizumab RP had similar primary structure (including polypeptide composition and glycosylation), secondary (higherorder) structure, and process-related substances and impurities [14]. Thermal stability, effect on tumor growth and metastasis is not thought to be impacted by bevacizumab therapy. HIF- $1 \alpha$ hypoxia-inducible factor $1 \alpha, H P V$ human papillomavirus, $m R C C$ metastatic renal carcinoma, $V E G F$ vascular endothelial growth factor

degradation rates, and general properties (protein concentration, volume, osmolality, $\mathrm{pH}$, appearance, color, and clarity) were also similar for ABP 215 and the bevacizumab RPs [14].

The biological and functional properties of ABP 215 and bevacizumab RP were also shown to be similar, as evidenced by similar relative target binding affinity to VEGF-A and in vitro potency for preventing VEGF binding to its receptor (as seen by inhibition of VEGF receptor signaling of tyrosine kinase activity). Furthermore, ABP 215 and bevacizumab RP had similar potency for inhibiting vascular growth in vitro, as demonstrated by similarity in proliferation of human umbilical vein endothelial cells. These findings indicate that ABP 215 and the RP have the same mechanism of action (MOA).

The next step in biosimilar development is the evaluation of clinical pharmacology. The pharmacokinetics (PK) of ABP 215 were assessed in a randomized, single-blind, single-dose, three-arm, parallel-group study in healthy subjects. Study findings confirmed the similarity between PK parameters of ABP 215 and bevacizumab RP [15]. A separate PK study conducted in healthy adult Japanese male subjects also showed similarity in PK parameters for ABP 215 and bevacizumab RP; results were similar to those reported in the global study [16]. Within each study, safety and tolerability findings were comparable for ABP 215 and the RP, with similar incidence of treatment-emergent adverse 

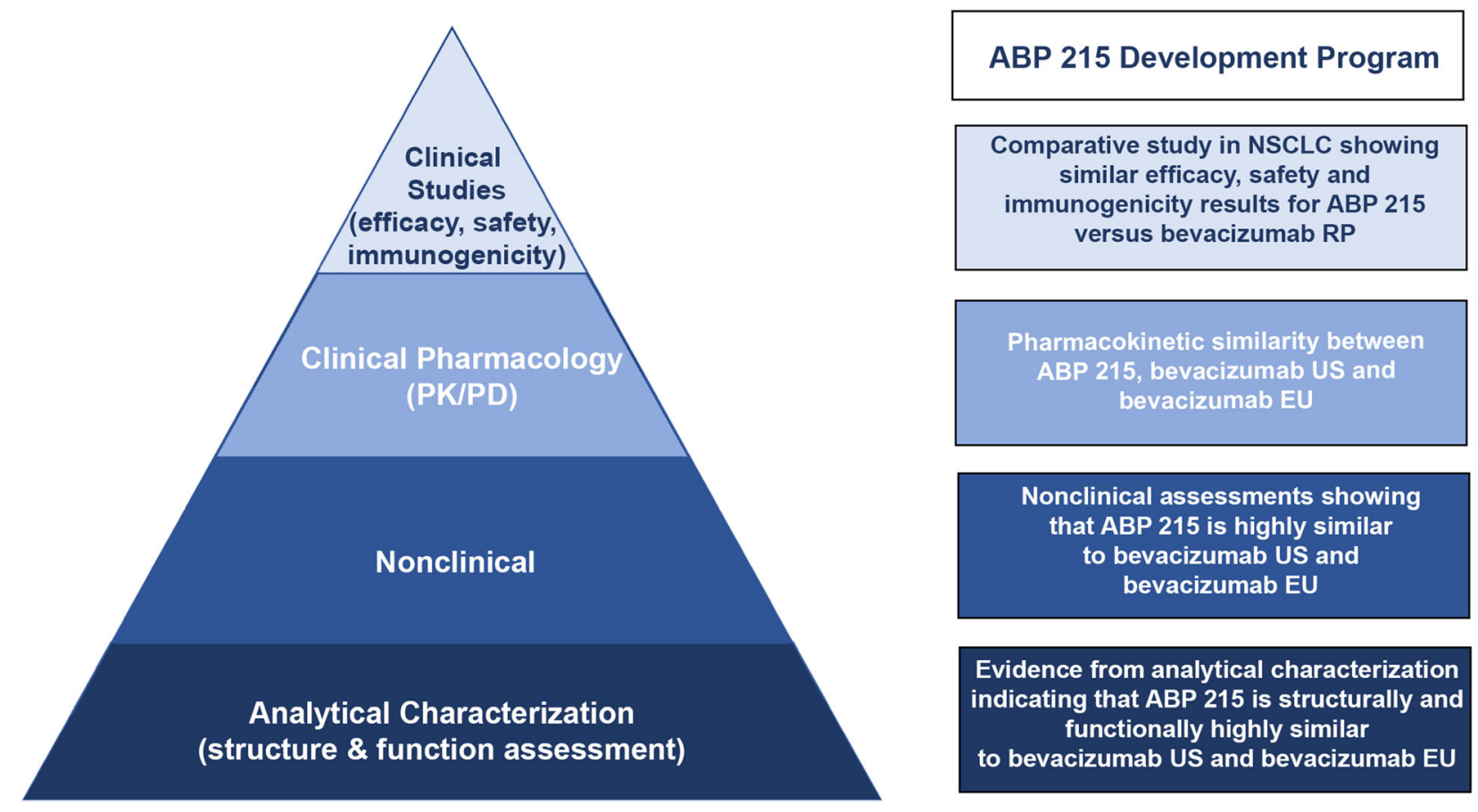

Fig. 2 "Totality of evidence" approach to demonstrating biosimilarity and overview of ABP 215 development program. EU European Union, NSCLC non-small cell

events (AEs) of all grades. No subjects in these studies developed binding or neutralizing antidrug antibodies (ADAs) [15, 16].

As the final step in the development of biosimilars to complete the TOE, a comparative clinical study was conducted using a single comparator. The efficacy and safety of ABP 215 compared with bevacizumab RP were evaluated in a randomized, double-blind, active-controlled, multicenter, multinational study (MAPLE), which enrolled adult patients with stage IV or recurrent non-squamous NSCLC receiving first-line carboplatin and paclitaxel [17]. This patient population is considered to be sensitive and well-characterized, with fewer potential confounding factors, thus suitable for comparison of a bevacizumab biosimilar to the $\mathrm{RP}[18,19]$.

A total of 642 patients were randomized to receive ABP $215(n=328)$ or bevacizumab RP $(n=314) 15 \mathrm{mg} / \mathrm{kg}$ every three weeks for six cycles along with carboplatin and paclitaxel every three weeks for $\geq 4$ cycles and $\leq 6$ cycles, respectively. The primary efficacy endpoint was lung cancer, $P D$ pharmacodynamics, $P K$ pharmacokinetics, $R P$ reference product, US United States

the risk ratio of the objective response rate (ORR), which was defined as the rate of best overall response of either complete response or partial response according to Response Evaluation Criteria in Solid Tumors (RECIST) v1.1. Responses were assessed by blinded, central, independent radiologists who reviewed radiographic images in the intent-to-treat population [17]. Objective responses were observed in 128 (39\%) patients receiving ABP 215 and 131 (41.7\%) receiving bevacizumab RP. The risk ratio for the ORR was 0.93 [90\% confidence interval (CI), 0.80-1.09]. The two-sided CI for the ORR fell within the prespecified margin for equivalence of 0.67-1.5, indicating similar clinical efficacy (Fig. 3) [17].

The overall type, severity, and frequency of AEs (Table 1) and AEs of interest were comparable for the ABP 215 and bevacizumab RP groups. The incidence of grade $\geq 3$ AEs of interest for the ABP 215 and bevacizumab RP groups, respectively, were hypertension (22 patients, $6.8 \%$; 17 patients, 5.5\%), gastrointestinal perforation (three patients, $0.9 \%$; four 
patients, $1.3 \%$ ), pulmonary hemorrhage (two patients, $0.6 \%$; five patients, $1.6 \%$ ), woundhealing complications (one patient, $0.3 \%$; two patients, $0.6 \%$ ), and proteinuria (one patient, $0.3 \%$; one patient, $0.3 \%$ ) [17]. The frequency of immunogenicity was similarly low for the two treatment groups. A total of four (1.4\%) patients in the ABP 215 and seven patients (2.5\%) in the bevacizumab RP arm developed binding ADAs, and for three patients $(1.0 \%$ for ABP 215 and $1.1 \%$ for bevacizumab RP) in each arm, binding antibodies were transient (i.e., results were negative at the last study assessment). No patient had a positive finding for neutralizing antibodies [17].

The nonclinical, preclinical, and clinical results reviewed here comprise the TOE that provides robust evidence that ABP 215 is highly similar to bevacizumab RP and has similar safety and efficacy in stage IV NSCLC [3].

\section{Extrapolation of Indications for ABP 215}

Extrapolation of indications is a unique component of regulatory approval of biosimilars. In this context, extrapolation refers to approval of the biosimilar for all of the indications for which the RP is approved except those protected by regulatory exclusivities. Justification for extrapolation is supported by all of the
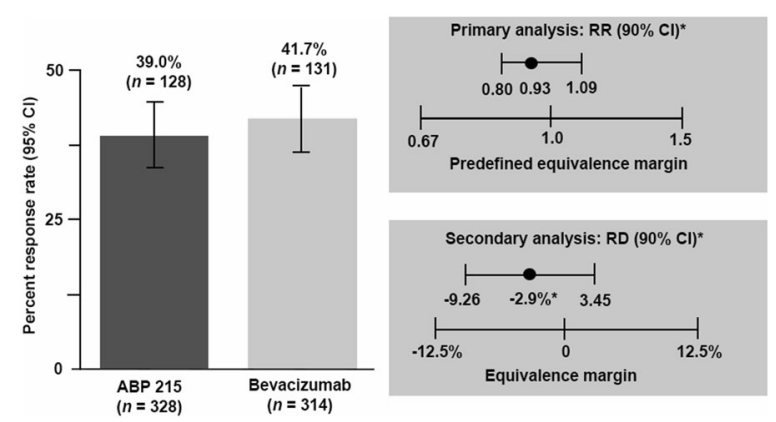

Fig. 3 Response rate and risk ratio of ORR [17]. ORR objective response rate (defined as complete or partial response based on RECIST v1.1). $R D$ risk difference, $R R$ risk ratio (based on a generalized linear model adjusted for randomization stratification factors of geographic region, Eastern Collaborative Oncology Group performance status, and sex)
Table 1 Safety findings in the comparative clinical trial of ABP 215 and bevacizumab (MAPLE) [17]

\begin{tabular}{|c|c|c|}
\hline $\mathrm{AE}, n(\%)$ & $\begin{array}{l}\text { ABP } 215 \\
(n=324)\end{array}$ & $\begin{array}{l}\text { Bevacizumab } \\
(n=309)\end{array}$ \\
\hline Any AE & $308(95.1)$ & $289(93.5)$ \\
\hline Any grade $\geq 3 \mathrm{AE}$ & $139(42.9)$ & $137(44.3)$ \\
\hline Any fatal AE & $13(4.0)$ & $11(3.6)$ \\
\hline Any serious $\mathrm{AE}$ & $85(26.2)$ & $71(23.0)$ \\
\hline $\begin{array}{l}\text { Any AE leading to } \\
\text { discontinuation of IP }\end{array}$ & $61(18.8)$ & $53(17.2)$ \\
\hline $\begin{array}{l}\text { Any AE leading to } \\
\text { discontinuation of any } \\
\text { component of } \\
\text { chemotherapy }\end{array}$ & $74(22.8)$ & $59(19.1)$ \\
\hline $\begin{array}{l}\text { Any AE leading to dose } \\
\text { delay of IP }\end{array}$ & $73(22.5)$ & $69(22.3)$ \\
\hline $\begin{array}{l}\text { Any AE leading to dose } \\
\text { delay of any component of } \\
\text { chemotherapy }\end{array}$ & $86(26.5)$ & $83(26.9)$ \\
\hline $\begin{array}{l}\text { Any AE leading to dose } \\
\text { reduction of any } \\
\text { component of } \\
\text { chemotherapy }\end{array}$ & $48(14.8)$ & $49(15.9)$ \\
\hline Grade $\geq 3$ EOIs & $102(31.5)$ & $99(32)$ \\
\hline \multicolumn{3}{|c|}{ Grade $\geq 3$ anti-VEGF-associated toxicities, $n(\%)$} \\
\hline Hypertension & $22(6.8)$ & $17(5.5)$ \\
\hline GI perforation & $3(0.9)$ & $4(1.3)$ \\
\hline Pulmonary hemorrhage & $2(0.6)$ & $5(1.6)$ \\
\hline $\begin{array}{l}\text { Wound healing } \\
\text { complications }\end{array}$ & $1(0.3)$ & $2(0.6)$ \\
\hline Proteinuria & $1(0.3)$ & $1(0.3)$ \\
\hline
\end{tabular}

$A E$ adverse event, $E O I$ event of interest, $G I$ gastrointestinal, $I P$ investigational product, $V E G F$ vascular endothelial growth factor

known factors that could affect safety or effectiveness in each indication $[3,17,20,21]$. 
Specific findings from the TOE for the similarity of ABP 215 and bevacizumab RP support the extrapolation of its indications to all indications for which the bevacizumab RP is approved $[1-3,20]$. The comprehensive analytical similarity assessment showed similarity between these two agents, which included similarity in the MOA [14]. The PK profiles for ABP 215 and bevacizumab RP were similar in healthy subjects $[15,16]$ as well as in patients with NSCLC [3, 17]. PK parameters for bevacizumab RP have been previously shown to be consistent across patients with different tumor types (e.g., NSCLC, colorectal cancer, metastatic breast cancer, etc.) [20]. These data provide justification supporting extrapolation for use of ABP 215 in all approved indications of the RP. The similarity of immunogenicity observations for ABP 215 and bevacizumab RP suggest that similar immunogenicity profiles may be expected for ABP 215 in all patient populations. The similar safety and efficacy profiles of ABP 215 and bevacizumab RP, also resembling those previously seen with bevacizumab RP, are supportive of similar safety and efficacy for ABP 215 when used for other indications. Furthermore, the similar safety and efficacy profiles for ABP 215 and bevacizumab RP for subgroups of patients with advanced NSCLC provide predictive data for safety and efficacy in other indications in which there is potential for PK interactions with chemotherapeutic therapies and other potential complications.

\section{Stability and Clinical Use of ABP 215}

As with bevacizumab RP, ABP 215 is supplied as a sterile solution in a single-use vial $(100 \mathrm{mg} /$ $4 \mathrm{~mL}$ or $400 \mathrm{mg} / 16 \mathrm{~mL}$ ). Similar to bevacizumab RP, ABP 215 should be administered intravenously in an infusion bag after appropriate dilution. The protocol for the correct method for storage and preparation of ABP 215 for administration is provided in Table 2 .

Preparation of ABP 215 product in some regions may be performed at oncology sites or at central pharmacy locations and then distributed to clinical oncology sites for administration. Therefore, it is important to understand
Table 2 The protocol for storage and preparation of ABP $215[1,2]$

Product storage and handling prior to administration

1. ABP 215 (MVASI $^{\mathrm{TM}}$ ) injection is a clear to slightly opalescent, colorless to pale yellow, sterile solution for intravenous infusion supplied as single-dose vials in the following strengths: $100 \mathrm{mg} / 4 \mathrm{~mL}$ and $400 \mathrm{mg} /$ $16 \mathrm{~mL}$

2. This product should be stored refrigerated at $2-8{ }^{\circ} \mathrm{C}$ $\left(36-46^{\circ} \mathrm{F}\right)$ until time of use and in the original carton to protect from light

3. Do not freeze or shake the vial or carton

Preparation

1. Visually inspect the vial for particulate matter and discoloration prior to preparation and administration. Discard vial if the solution is cloudy, discolored, or contains particulate matter

2. Determine the dose $(\mathrm{mg})$ of ABP 215 product as defined in the package insert

3. Calculate the volume of the ABP 215 solution needed

4. Using appropriate aseptic technique, withdraw the necessary amount of ABP 215 and dilute in an infusion bag containing $100 \mathrm{~mL}$ of $0.9 \%$ Sodium Chloride Injection, USP

\section{DO NOT ADMINISTER OR MIX WITH GLUCOSE [1] OR DEXTROSE [2] SOLUTION}

6. Gently invert the bag to mix the solution

7. Discard any unused portion left in the vial, as the product contains no preservatives

8. Store diluted ABP 215 in polyvinylchloride or polyolefin bags containing $0.9 \%$ Sodium Chloride Injection, USP; should be stored at $2-8{ }^{\circ} \mathrm{C}\left(36-46^{\circ} \mathrm{F}\right)$ for no more than $8 \mathrm{~h}$ prior to use. Do not freeze

Bold represent the areas for attention

the stability of ABP 215 under the conditions of use; the physicochemical stability of ABP 215 


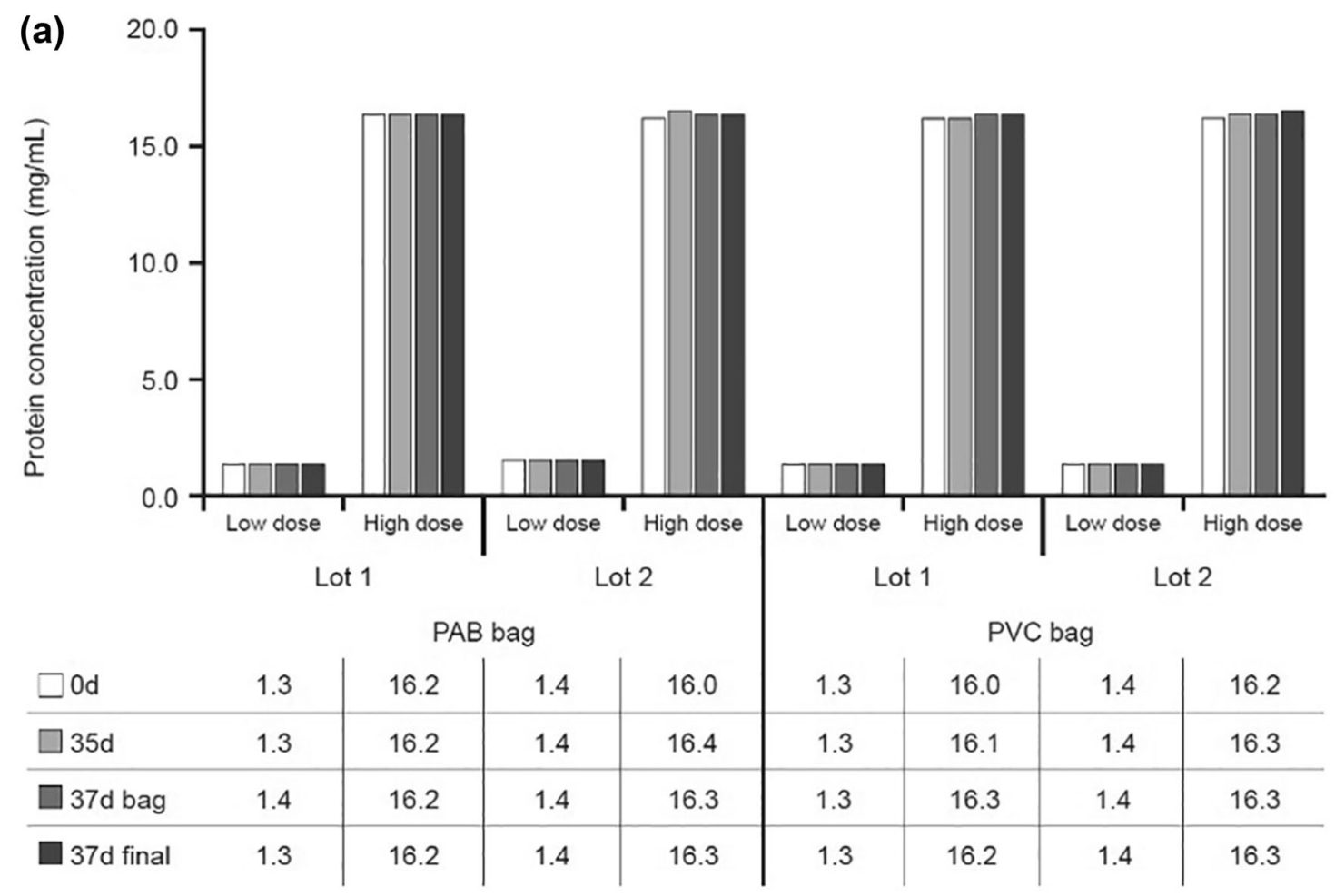

(b)

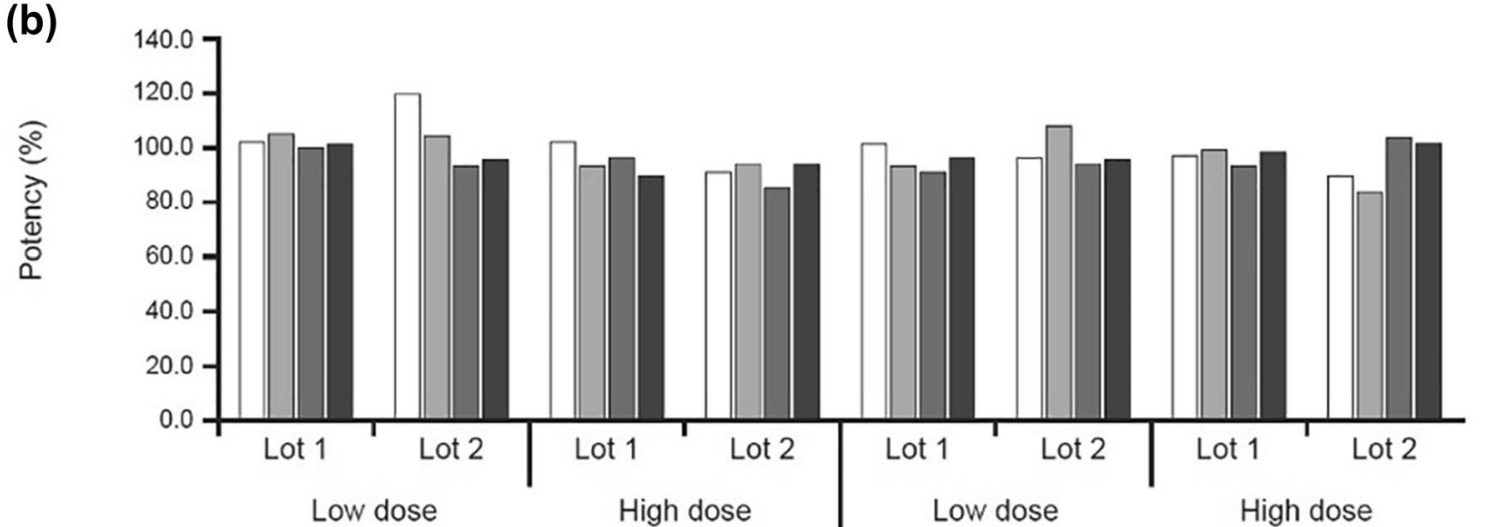

\begin{tabular}{|c|c|c|c|c|c|c|c|c|}
\hline \multirow[b]{3}{*}{$\square 0 d$} & \multicolumn{2}{|c|}{ Low dose } & \multicolumn{2}{|c|}{ High dose } & \multicolumn{2}{|c|}{ Low dose } & \multicolumn{2}{|c|}{ High dose } \\
\hline & \multicolumn{4}{|c|}{ PAB bag } & \multicolumn{4}{|c|}{ PVC bag } \\
\hline & 102 & 120 & 102 & 91 & 101 & 96 & 97 & 89 \\
\hline$\square 35 d$ & 105 & 104 & 93 & 94 & 93 & 108 & 99 & 83 \\
\hline$\square 37 d$ bag & 100 & 93 & 96 & 85 & 91 & 94 & 93 & 103 \\
\hline$\square 37 d$ final & 101 & 95 & 89 & 94 & 96 & 95 & 98 & 101 \\
\hline
\end{tabular}

Fig. 4 Physicochemical stability of ABP 215 after storage in $\mathrm{PAB}$ and PVC bags at $2-8{ }^{\circ} \mathrm{C}$ for 35 days (35 days), $30{ }^{\circ} \mathrm{C}$ for 2 days ( 37 days bag), and infusion at room temperature for $90 \mathrm{~min}$ (37 days final) [22]. a Protein concentration; $\mathbf{b}$ potency for inhibiting proliferation of human umbilical endothelial cells. $P A B$ partial additive bag, $P V C$ polyvinyl chloride (Reprint with permission from Seckute et al. [22]) 
under in-use conditions was therefore assessed [22]. Infusion bags containing formulation buffer, ABP $2151.4 \mathrm{mg} / \mathrm{mL}$, and $16.5 \mathrm{mg} / \mathrm{mL}$ were prepared and stored at $2-8{ }^{\circ} \mathrm{C}$ for 35 days followed by storage at $30^{\circ} \mathrm{C}$ for $48 \mathrm{~h}$. No meaningful changes were seen in results from three purity assays. Protein recovery following the study storage periods in the intravenous bag and infusion system ranged from $99.4 \%$ to $101.7 \%$, indicating no protein (product) loss (Fig. 4a). Results from assays for inhibition of human umbilical vein epithelial cell proliferation indicated no notable loss in potency (Fig. 4b). Visual inspection revealed no potentially proteinaceous particles, and no trends were found for subvisible particulate matter in the drug product and control formulation buffer.

\section{DISCUSSION}

The TOE from all of the studies of ABP 215 supports the conclusion that ABP 215 is highly similar to bevacizumab RP. No clinically meaningful differences were found in function, purity, potency, PK, clinical efficacy, safety, or immunogenicity, consistent with the underlying definition of a biosimilar based on the standards of regulatory agencies across the globe [21, 23-27]. The robust scientific evidence on ABP 215 presented here supports the use of ABP 215 as a biosimilar to bevacizumab RP, thus offering an additional treatment option for the approved indications of bevacizumab. Furthermore, the TOE supports the scientific justification for extrapolation to all the approved indications of bevacizumab RP [3].

Biosimilars provide alternative treatment options and sources for existing biologic agents. This may address some of the challenges with drug shortages seen in oncology settings. It is hoped that experience in biologics manufacturing along with supply chain reliability would provide quality biosimilars in a timely way, resulting in a positive impact on patient outcomes [28-30].

While many pharmaceutical companies claim to have a record of reliable drug supply, published data supporting such claims are limited. A recent analysis of the reliability of the drug supply in Europe from 2012 through July 31,2019 showed that the rate of on-time, in-full delivery from a manufacturing facility to the first economic customer was $\geq 99 \%$ for all study years [31].

The availability of bevacizumab RP and its biosimilars is important, as these agents are used in the treatment of several cancers [19] and have promise for use in new therapeutic combinations such as cancer immunotherapies [32]. With supply chain reliability, biosimilars may potentially prevent or mitigate drug shortages, by providing additional therapeutic options.

\section{CONCLUSION}

The preparation and administration protocols for ABP 215 are straightforward, and the product is stable under normal conditions of use. The robust data that forms the TOE for ABP 215 as a biosimilar for bevacizumab RP should provide oncologists with assurance about using ABP 215 in treating all approved indications per the prescribing information in their country or region.

\section{ACKNOWLEDGEMENTS}

Funding. Funding for medical writing and editing support and for the Rapid Service Fee was provided by Amgen Inc., Thousand Oaks, CA.

Editorial Assistance. Medical writing support, funded by Amgen, Inc., was provided by Annette F. Skorupa, PhD, Innovation Communications Group, Inc., New York, NY, USA under the direction of Monica Ramchandani, PhD, Amgen, Inc., California, USA.

Authorship. All named authors meet the International Committee of Medical Journal Editors (ICMJE) criteria for authorship for this article, take responsibility for the integrity of the work as a whole, and have given their approval for this version to be published. 
Authorship Contributions. Both authors contributed to the conceptualization, development, and review of this manuscript.

Disclosures. Vladimir Hanes is an Amgen employee and stockholder. Jerome Goldschmidt has received speaker's bureau fees from BMS and consulting fees from Amgen.

Compliance with Ethics Guidelines. This article is based on previously conducted studies and does not contain any studies with human participants or animals performed by any of the authors.

Data Availability. Data sharing is not applicable to this article as no datasets were generated or analyzed for this manuscript.

Open Access. This article is licensed under a Creative Commons Attribution-NonCommercial 4.0 International License, which permits any non-commercial use, sharing, adaptation, distribution and reproduction in any medium or format, as long as you give appropriate credit to the original author(s) and the source, provide a link to the Creative Commons licence, and indicate if changes were made. The images or other third party material in this article are included in the article's Creative Commons licence, unless indicated otherwise in a credit line to the material. If material is not included in the article's Creative Commons licence and your intended use is not permitted by statutory regulation or exceeds the permitted use, you will need to obtain permission directly from the copyright holder. To view a copy of this licence, visit http://creativecommons.org/licenses/by$\mathrm{nc} / 4.0 /$.

\section{REFERENCES}

1. $\mathrm{MVASI}^{\mathrm{TM}}$ (bevacizumab-awwb) for injection, for intravenous use. Prescribing information. Amgen Inc., Thousand Oaks, CA: 2020. https://www.pi. amgen.com/ /media/amgen/repositorysites/piamgen-com/mvasi/mvasi_pi_hcp_english.pdf. Accessed August 27, 2020.
2. MVASI. Summary of product characteristics. Amgen Europe B.V., the Netherlands: 18 December 2020. https://www.ema.europa.eu/en/medicines/human/ EPAR/mvasi\#productinformation-section. Accessed August 27, 2020.

3. Thomas M, Thatcher N, Goldschmidt J, Ohe Y, McBride HJ, Hanes V. Totality of evidence in the development of ABP 215, an approved bevacizumab biosimilar. Immunotherapy. 2019;11(5):1337-51.

4. Apte RS, Chen DS, Ferrara N. VEGF in signaling and disease: beyond discovery and development. Cell. 2019;176:1248-64.

5. Markus R, Liu J, Ramchandani M, Landa D, Born T, Kaur P. Developing the totality of evidence for biosimilars: regulatory considerations and building confidence for the healthcare community. BioDrugs. 2017;31(3):175-87.

6. Kozlowski S, Woodcock J, Midthun K, Sherman RB. Developing the nation's biosimilars program. N Engl J Med. 2011;365(5):385-8.

7. U.S. Department of Health and Human Services. Scientific considerations in demonstrating biosimilarity to a reference product. Guidance for industry. 2015. https://www.fda.gov/downloads/Drugs/ GuidanceComplianceRegulatoryInformation/ Guidances/UCM291128.pdf. Accessed 24 September 2020 .

8. U.S. Department of Health and Human Services, Food and Drug Administration, Center for Drug Evaluation and Research, Center for Biologics Evaluation and Research. Quality considerations in demonstrating biosimilarity of a therapeutic protein product to a reference product. Guidance for industry. 2015. https://www.fda.gov/downloads/ drugs/guidancecomplianceregulatoryinformation/ guidances/ucm291134.pdf. Accessed 24 September 2020.

9. US Department of Health and Human Services, Food and Drug Administration, Center for Drug Evaluation and Research, Center for Biologics Evaluation and Research. Clinical pharmacology data to support a demonstration of biosimilarity to a reference product. Guidance for industry. 2016. https://www.fda.gov/downloads/Drugs/ GuidanceComplianceRegulatoryInformation/ Guidances/UCM397017.pdf. Accessed 24 September 2020 .

10. European Medicines Agency, Committee for Medicinal Products for Human Use. Guideline on similar biological medicinal products containing monoclonal antibodies-non-clinical and clinical issues. 2012. https://www.ema.europa.eu/docs/en GB/document_library/Scientific_guideline/2012/ 
06/WC500128686.pdf. Accessed 24 September 2020.

11. European Medicines Agency. Guideline on similar biological medicinal products containing biotechnology-derived proteins as active substance: quality issues (revision 1). 2014. https://www.ema.europa. eu/docs/en_GB/document_library/Scientific_ guideline/2014/06/WC500167838.pdf. Accessed 24 September 2020.

12. European Medicines Agency. Guideline on similar biological medicinal products (revision 1). 2014. https://www.ema.europa.eu/en/documents/ scientific-guideline/guideline-similar-biologicalmedicinal-products-rev1_en.pdf. Accessed 24 September 2020.

13. Nathan J, Ramchandani M, Kaur P. Manufacturing of Biologics. In: Biologic and Systemic Agents in Dermatology. 2018.

14. Seo N, Polozova A, Zhang M, Yates Z, Cao S, Li H, et al. Analytical and functional similarity of Amgen biosimilar 215 to bevacizumab. MAbs. 2018;10: 678-91.

15. Markus R, Chow V, Pan Z, Hanes V. A phase I, randomized, single-dose study evaluating the pharmacokinetic equivalence of biosimilar ABP 215 and bevacizumab in healthy adult men. Cancer Chemother Pharmacol. 2017;80(4):755-62.

16. Hanes V, Chow V, Pan Z, Markus R. A randomized, single-blind, single-dose study to assess the pharmacokinetic equivalence of the biosimilar ABP 215 and bevacizumab in healthy Japanese male subjects. Cancer Chemother Pharmacol. 2018;82: 899-905.

17. Thatcher N, Thomas M, Paz-Ares Rodriguez L, Ostoros G, Pan J, Goldschmidt JH, et al. Efficacy and safety of the biosimilar ABP 215 compared with bevacizumab in patients with advanced non-small cell lung cancer (MAPLE): a randomized, doubleblind, phase III study. Clin Cancer Res. 2019;25(7): 2088-95.

18. Isakov L, Jin B, Jacobs IA. Statistical primer on biosimilar clinical development. Am J Ther. 2016;23:e1903-10.

19. Melosky B, Reardon DA, Nixon AB, Subramanian J, Bair AH, Jacobs I. Bevacizumab biosimilars: scientific justification for extrapolation of indications. Future Oncol. 2018;14:2507-20.

20. U.S. Food and Drug Administration. Background information for the Oncologic Drugs Advisory Committee (ODAC) 13 July 2017. Biologics License Application for ABP 215. Submitted 08 June 2017. Amgen Inc., Thousand Oaks. https://www.fda.gov/ media/106549/download. Accessed August 27, 2020.

21. Thill M, Thatcher N, Hanes V, Lyman V. Biosimilars: what the oncologist should know. Future Oncol. 2019;15:1147-65.

22. Seckute J, Castellanos I, Bane S. Physiochemical stability of the bevacizumab biosimilar, ABP 215, after preparation and storage in intravenous bags. Generics. Biosimilars. Initiat. J. (GaBI Journal). 2020;9(4):155-62. https://doi.org/10.5639/gabij. 2020.0904 .026 .

23. U.S. Food and Drug Administration. Questions and answers on biosimilar development and the BPCI Act. Guidance for Industry. December 2018. https://www.fda.gov/media/119258/download. Accessed August 27, 2020.

24. European Medicines Agency. Guideline on similar biological medicinal products. October 2014. https://www.ema.europa.eu/en/documents/ scientific-guideline/guideline-similar-biologicalmedicinal-products-rev1_en.pdf. Accessed September $23,2020$.

25. U.S. Food and Drug Administration. Center for Drug Evaluation and Research. Scientific considerations in demonstrating biosimilarity to a reference product. Guidance for industry. 2015. https://www. fda.gov/media/82647/download. Accessed August 27,2020 .

26. Japan Generic Medicines Association. April 19, 2013. Interim Translation of Notification of ELD, PFSB, MHLW; Yakushokushinsa No0304007. 2009.

27. World Health Organization. Expert Committee on Biological Standardization. Guidelines on evaluation of similar biotherapeutic products (SBPs). 2009. https://www.who.int/biologicals/areas/ biological_therapeutics/BIOTHERAPEUTICS_FOR_ WEB_22APRIL2010.pdf. Accessed August 27, 2020.

28. Li E, Subramanian J, Anderson S, Thomas D, McKinley J, Jacobs IA. Development of biosimilars in an era of oncologic drug shortages. Drug Des Devel Ther. 2015;9:3247-55.

29. Dranitsaris G, Jacobs I, Kirchoff C, Popovian R, Shane LG. Drug tendering: drug supply and shortage implications for the uptake of biosimilars. ClinicoEcon Outcomes Res. 2017;9:573-84.

30. Kabir ER, Moreino SS, Siam MKS. The breakthrough of biosimilars: a twist in the narrative of biological therapy. Biomolecules. 2019;9:410.

31. Schipper R, Middelkoop K, Biniass B, Hippenmeyer J. Assessment of drug supply reliability in Europe by evaluating on time in full (OTIF) delivery. Presented 
at the 22nd Annual British Oncology Pharmacy Association (BOPA)/International Society of Oncology Pharmacy Practitioners (ISOPP) Symposium. October 10 to October 13, 2019, London, UK. https://www.bopa.org.uk/resources/assessment-ofdrug-supply-reliability-in-europe-by-evaluating-ontime-in-full-otif-delivery/.
32. Chen DS, Hurwitz H. Combinations of bevacizumab with cancer immunotherapy. Cancer J. 2018;24:193-204. 